be accounted for except by profound physiological disturbances such as are found in birds during migration.

It is difficult not to add, although it is not argument, that if Dr. Felt had once seen a hundred thousand butterflies going headlong against the wind, or coming out of the bare desert like a thin haze, or flying out to sea without taking any other interest in a steamer than that necessary to avoid it, he would realise the complete lack of identity between this and the willynilly drift that carries aphids to Spitsbergen or mosquitoes and house-flies to the Rebecca Shoal Lighthouse.

Ministry of Agriculture, Cairo, Egypt, June ro.

\section{Series Spectra of the First Long Period.}

THE regular and irregular doublet laws have been applied to some lines which appear in the highpotential spark of scandium, titanium, vanadium, and chromium, and those listed in the table appear to be the first members of the $P$ doublets of Sc III to $\mathrm{Cr}$ VI. For convenience, those of $\mathrm{K} \mathrm{I}$ and $\mathrm{Ca}$ II have been included from Fowler's "Series in Line Spectra."

\begin{tabular}{|c|c|c|c|c|}
\hline Element. & $\lambda$. & $I$. & $\nu$. & $\Delta \nu$. \\
\hline K I & $\begin{array}{l}7664^{\circ} \cdot 94 \\
7699 \cdot 01\end{array}$ & $\begin{array}{l}\text { Io } R \\
\text { Io } R\end{array}$ & $\begin{array}{l}\text { I } 3042 \cdot 8 \\
\text { I } 2985 \cdot \mathrm{I}\end{array}$ & $57 \cdot 7$ \\
\hline Ca II & $\begin{array}{l}3933 \cdot 7 \\
3968 \cdot 5\end{array}$ & $\begin{array}{l}\text { Io } R \\
\text { Io } R\end{array}$ & $\begin{array}{l}254 \mathrm{I} 4.4 \\
25 \mathrm{I} 9 \mathrm{I} \cdot 6\end{array}$ & $222 \cdot 8$ \\
\hline Sc III & $\begin{array}{l}2699 \cdot 9 \\
2734 \cdot 9\end{array}$ & $\begin{array}{r}\text { IO } \\
9\end{array}$ & $\begin{array}{l}37038 \cdot 4 \\
36564 \cdot 4\end{array}$ & 474 \\
\hline Ti IV & $\begin{array}{l}2067 \cdot 6 \\
2103 \cdot 4\end{array}$ & $\begin{array}{l}9 \\
8\end{array}$ & $\begin{array}{l}48363 \\
47542\end{array}$ & $82 \mathrm{I}$ \\
\hline V V & $\begin{array}{l}1680 \cdot 4 \\
\text { I } 722 \cdot 7\end{array}$ & $\begin{array}{l}5 \\
3\end{array}$ & $\begin{array}{l}59510 \\
58048\end{array}$ & $\mathrm{r}_{4} 62$ \\
\hline $\mathrm{Cr}$ VI & $\begin{array}{l}\text { I } 446 \cdot 7 \\
\text { I } 498 \cdot 0\end{array}$ & $\begin{array}{l}4 \\
2\end{array}$ & $\begin{array}{l}69123 \\
6675^{6}\end{array}$ & 2367 \\
\hline
\end{tabular}

The wave-lengths were measured in vacuo on a twometre grating having 30,000 lines per inch, giving an average dispersion of $4.5 \AA$.U. per $\mathrm{mm}$.

There is no doubt that from scandium onward the intensity of these pairs falls steadily as indicated, but there is no direct comparison intended between these and potassium or calcium. It may be said, however, that calcium and scandium were taken on the same plates in some cases, and the calcium doublet was strongly reversed and apparently very much more intense than that for scandium.

When the intensity ratio of the two lines of each pair is considered, it is found that the shorter line is always the more intense of the two.

The corresponding doublet for Mn VII falls in a region having many strong lines, mostly due to silicon, and so no definite conclusion could be arrived at regarding its existence.

The origin of these pairs seems unexplained, since each of these elements from calcium onward is supposed to have but two electrons in the $N$ levels, unless we assume that when these are removed some of the $M$ electrons move out to take their places in a manner similar to that discussed by Catalán (Phil. Trans., A, vol. 223, p. I66). Some such assumption seems necessary to explain chemical and magnetic results. It seems possible, also, that there may be some connexion between this and the decreasing intensity of the pairs.

The doublet for Sc III was arrived at independently by Mr. S. Smith, who spent considerable time looking for further series relations for this system, but while several pairs having the same separation are known, no certain results have been found. R. J. LANG.

University of Alberta,

Edmonton, Canada, May 25.

\section{Technical and Intellectual Values.}

IN the leading article in NATURE of June $\mathrm{r} 2$, the Association of Teachers in Technical Institutions is invited to publish the philosophy of that branch of education in which its members are specialists. A series of principles is urgently required, and this the Association has formulated, partly philosophical, partly scientific. Control experiments to check our hypotheses are now in the process of performance through the medium of Lord Emmott's Committee of Inquiry into Technical Education, which was suggested, and the preliminary work undertaken by the A.T.T.I., but which is now under the control of an executive committee representative of industry, local education authorities, learned institutions, and technical teachers, with Mr. J. Wickham Murray as its honorary secretary. The guiding principles which are asked for will soon be in a form suitable for publication, and will then be submitted to the reading public for criticism and suggestion.

The urgent need for their formulation and publication is shown by recent speeches of the president of the Board of Education. In his opinion, secondary education is the preparation for a university education destined to provide the 'governing classes' - to use his words as reported in the press. Such a typically constricted outlook must be widened. The function of a government does not end with the manipulation of Emergency Powers Acts. Industry and commerce must be encouraged and fostered. Whether governmental philosophy be individualist or collectivist, we shall require men with technological training and capable of the application of science to the industrial world. Education must include education for service as well as for government, and this service must be intelligent: not a clumsy translation of good intentions into feeble practice.

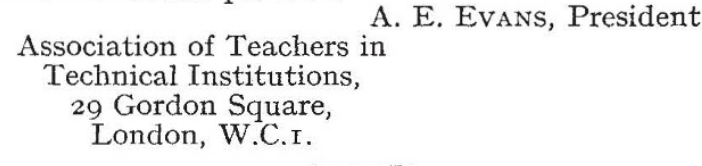

Natural History of the New Hebrides.

IN a few months my brother and I are going to the New Hebrides, in the Pacific Ocean, to explore the interior of the largest island, to collect the fauna, to study animal reproduction in a climate that is almost constant throughout the year, and to undertake other work of a more special nature. Particular interest attaches to a large lake on one of the islands, said to be almost the only lake in Melanesia. We are financed in part by the Trustees of the Percy Sladen Memorial Fund.

If any reader of NATURE who is a specialist in any group of terrestrial or fresh-water animals or their parasites would care to communicate with me, I should be glad to make a particular point of collecting that group and of sending the specimens to him on our return, provided that he will undertake to work out the collection and subject to the approval of the Percy Sladen Trustees.

Department of Zoology and

Comparative Anatomy,

University Museum, Oxford. 